\title{
The Study on Gender Bias among Adult and Middle Aged Women
}

\author{
Dr. Tabinda Iqbal ${ }^{1 *}$
}

\section{ABSTRACT}

Millions of women's are raised in an environment of neglect, overwork, and often, abuse, simply because they are female. In many countries women's are fed less than their brothers, forced to work harder, provided less schooling and denied equal access to medical care. They marry earlier and face greater risks of dying in adolescent and early adult hood. Their impaired health and lost opportunities exact a terrible toll on society and on future generations. South Asian countries and India are societies with strong patriarchal norms, a high degree of son preference and pervasive gender Discriminations.

Gender discrimination and continued gender gap have been the most persistent social problems facing the global community. These problems have received considerable attention particularly during the past three decades through a series of initiatives at international, regional and national levels. This process was formally initiated through the programmes centring on the international women's year in 1975.

However, the overall economic development of a nation requires maximum utilization of human resources without any discrimination on the basis of caste, creed, religion or sex. In this particular study the investigator has tried to "the study on gender bias among adult and middle aged women”. The sample of the study comprises of 300 adult and middle aged women. Gender bias scale developed by investigator Department of education A.M.U, was used for data collection, t-test when applied on data revealed that the result is 0.5 level of confidence.

Keywords: Gender, Adult, Middle, Women, Bias

Over the last two decades, gender and development has indeed been discussed a great deal. There have been scores of conference, trainings and workshops on their subjects. Generally, the discussions have focused on ensuring equal opportunities for women and men particularly on social and economic rights, mainly in poor economies where human deprivations is frequently depicted in terms of limited and unequal access to food, nutrition, health care, educational and job opportunities. consequently, women's political rights have been ignored or neglected, as has been argued by social thinkers, that as a priority women need adequate food, basic health care services and educational opportunities rather than right to participation in politics or public decision making in the 1950's many of the newly independent countries began their developmental activities on the models of the western countries. It was believed that

\footnotetext{
${ }^{1}$ Post Doctoral Fellow, Dept of Education, A.M.U, Aligarh

*Corresponding Author

(C) 2015 I T Iqbal; licensee IJIP. This is an Open Access Research distributed under the terms of the Creative Commons Attribution License (http://creativecommons.org/licenses/by/2.0), which permits unrestricted use, distribution, and reproduction in any Medium, provided the original work is properly cited.
} 
industrialization and use of modern techniques in agricultural activities would usher in growth and development for the country as a whole in general and the backward class including women in particular. On these presumptions, Governments of developing countries were betting on the strong assumptions that the benefits of development would trickle down to poor majorities, and gradually whole communities would prosper .very little attention was paid on poor segment of the population particularly the women. Women's contribution to the household and to the economy was neither recognized nor valued at that time.

\section{Definition:}

According to Macmillan dictionary unfair difference in the treatment of men or women because of their sex. Sexism, a term coined in the mid-20th century, Shorter Oxford English.

Dictionary, 6th edition is the belief or attitude that one gender or sex is inferior to, less Competent, or less valuable than the other. ...

When examining gender bias, it is important to define and understand the term.

Gender is defined by the American Heritage Dictionary as "classification of sex."

According to this same source, bias is defined as "preference or inclination that inhibits impartiality; prejudice" (American Heritage Dictionary, 1983). Thus gender bias is separation of gender in a way which prefers one sex over the other. Gender bias in technology refers to preference for or favouring of one sex over the other in computer use and/or access, software use and/or manufacturing, and Internet use and content. As can be seen, gender bias in technology is a multifaceted and complex issue.

\section{Statement of the problem:}

The investigator has tried to study the gender bias among adult and middle aged women

\section{REVIEW OF THE LITERATURE}

A careful review of the search journals, books dissertations, and other sources of information on the problem to be investigated is one of the important steps in the planning of any research study .Thus, a review of the related literature must precede any well- planned research study. The purpose of the review of previous literature is to collect and synthesize prior studies related to the present study. This in turn, helps the investigator in building a better perspective for further research

Goldberg, (1984) investigated gender differences experienced in work and in the family influence class consciousness. Thirty-four women employed as clerical workers were interviewed. Their responses indicate that the increasing demands of the workplace force women to confront the dual expectations of home and the office. Women who belong to organizations dedicated to improving working conditions show an increasing awareness of the way their traditional family roles are integrated with their roles in the public sector. A new theory of 
consciousness must take into account the consciousness that arises when people are confronted by the contradictory expectations of the workplace and the family.

Game \& Pringle (1984) examined difference by experience of paid work and trade unionism. The aim of the research was to develop an understanding of the 35 relationship between gender, the labour process and technological change. The research covers case studies of six industries over the entire post-war period in Australia: the white goods industry; banking; retailing; computing; nursing; and housework. The forms of control of the labour process (predominantly patriarchal) and the operation of social control through the sexual division of labour define jobs as either 'male' or 'female.' There appears to be nothing inherent in any job which makes it male or female, but deskilling is managed by management and men by further gender differentiation and measuring of men's work against 'women's work.' The traditional trade union assumption that female involvement in work leads to deskilling and low wages is challenged, the authors arguing that the reverse is true. The legality of sex differentiations as opposed to sex discrimination in the Australian sex discrimination act allows the process to continue unchallenged.

Gaarder (2000) examined how the politics of gender have influenced and shaped the modern debates over sexual abuse and memory. It explores the level of scrutiny applied to women accuses, the language used to characterize women within the debate, and why the sexual abuse memories of women have become the specific and focused target of 'false memory' proponents and the media. A comparison is made between tactically similar backlash movements against women and feminism.

Tomori, et. al. (2000) investigated psychological risk in adolescents and assessed gender differences in the frequency of their occurrence. A specially designed questionnaire, which included validated scales for the evaluation of depression (Zung self - rating depression scale) and self-esteem (Rosenberg self - esteem scale), was administered to a representative sample of Solvenian adolescents. Data analysis revealed several significant gender differences. Girls more often than boys reported family conflict, personal problems, physical inactivity, attempts to control body weight, use of psychoactive drugs, suicidal ideation, and suicide attempts. Their level of depression was higher and self-esteem lower when compared with their male counterparts. Boys more often than girls indicated that they watched a great deal of television, were the victims of peer violence, and drank alcohol.

\section{Significance of the study:}

Women in India face discrimination in terms of several political and economic opportunities as a result of their inferior status. Majority of women cannot inherit parental property and political and employment participation are very limited. Gender inequalities prevail in work, education, allocation of food, health care and fertility choices. On the other hand, at the family level women 
are exclusively burdened with household chores- cooking, cleaning, collecting fuel and water and caring elderly and children (Arokiasamy, 2003).

Therefore, it is clear that women's problems are a current issue of the present day society. So the investigator with all the limitations modestly attempted to understand gender bias among women. The investigator has selected two age groups of women adult and middle aged women for the study. The choice of two age groups was made in order to find out the effect of aging upon the variables of the study. Middle aged women may suffer more discrimination than adult women (at least on emotional level) due to their decreased energy. It is possible that they also suffer from lack of care which they need due to the aging process.

\section{OBJECTIVES}

The present study was conducted to achieve the following objectives and sub objectives.

Main objectives along with sub objectives are given below:

\section{Objective-1:}

To compare the level of gender bias amongst adult women and middle aged women.

\section{Sub objectives}

To achieve the objective 1 , following sub objectives were formulated.

1.1. To compare the level of gender bias amongst slum and non slum women.

\section{HYPOTHESES}

In order to achieve the above mentioned objectives the following hypothesis and sub Hypothesis were formulated and tested:

\section{Hypotheses-1:}

There will be no significant difference in the level of gender bias amongst adult women and middle-aged women.

\section{Sub Hypotheses}

1.1. There will be no significant difference in the level of gender bias amongst slums and none slums women.

\section{POPULATION AND SAMPLE:}

The sample present study comprised of 300 adult and Middle aged women.

Approximately 500 houses are there in the vicinity of Aligarh Muslim University, more specifically in medical quarters and old Sir Syed Nagar. We have selected only 52 houses on random basis. Approximately 450 women were living in the outskirts of Jeevangarh and Jamalpur. They live with their families in very poor conditions. They live in "jhopdis and jhuggi”. Out of 450 having selected 84 slum women on random selected. Further we had to select adult and middle aged women separately from slum areas women group.

\section{RESEARCH TOOLS}

Gender bias scale developed by investigator to measure the gender bias among adult and middle aged women. 


\section{Statistical technique used:}

$\mathrm{t}$-test have been used for the study.

Objective 1: To compare the gender bias amongst adult women and middle aged women.

Null Hypothesis 1: There will be no significant difference in the gender bias amongst adult women and middle-aged women.

Table 1.0, Comparison of the scores of Gender bias between adult and middle aged women

\begin{tabular}{|l|l|l|l|l|l|l|}
\hline Groups & N & Mean & SD & SED & t-value & Significance \\
\hline Adult age women & 164 & 94.28 & 13.80 & & & \\
\cline { 1 - 4 } Middle aged women & 136 & 96.26 & 15.83 & 1.078 & 1.16 & NSI \\
\hline
\end{tabular}

The Mean score for adult age women sample $(\mathrm{N}=164)$ is $94.28, \mathrm{SD}=13.80$ and for middle aged women sample (136) Mean is 96.26, $\mathrm{SD}=15.83$, and SED $=1.078$. The calculated t-value is 1.16.which is not significant. Therefore null hypothesis no. 1 is accepted.

Sub Objective 1.1 To compare the gender bias amongst slum and non-slum women.

Null Hypothesis 1.1 : There will be no significant difference in the gender bias amongst slum and non slum women.

Table 1.1, Comparison of the scores of gender bias between slum and non slum women.

\begin{tabular}{|l|l|l|l|l|l|l|}
\hline Groups & N & Mean & SD & SED & t-value & Significance \\
\hline Slum & 84 & 101.72 & 10.280 & & & \\
\hline Non-slum & 216 & 92.64 & 15.462 & 1.122 & 4.97 & $>0.01$ level \\
\hline
\end{tabular}

The Mean score for slum women sample is 101.72, SD $=10.280$ and for non slum women sample Mean is 92.64, $\mathrm{SD}=15.462$, and $\mathrm{SED}=1.122$. The calculated t-value is 4.97 . Which is significant at 0.01 levels. The null-hypothesis no. 1.2 is rejected. Therefore, gender bias is more operative in slum women.

Sub Objective 1.2: To compare the gender bias amongst slum adult and slum middle aged women.

Null Hypothesis 1.2: There will be no significant difference in the gender bias amongst slum adult and slum middle aged women. 
The Study on Gender Bias among Adult and Middle Aged Women

Table 1.2 Comparison of the scores of Gender bias between slum adult women and slum middle aged women

\begin{tabular}{|l|l|l|l|l|l|l|}
\hline Groups & N & Mean & SD & SED & t-value & Significance \\
\cline { 1 - 5 } slum adult women & 48 & 102.70 & 10.34 & & & \\
\cline { 1 - 4 } $\begin{array}{l}\text { Slum middle aged } \\
\text { women }\end{array}$ & 34 & 99.94 & 10.19 & 1.494 & 1.20 & NSI \\
\hline
\end{tabular}

The Mean score for slum adult women sample is 102.70 , SD $=10.34$ and for slum middle aged women sample Mean is 99.94, $\mathrm{SD}=10.19$, and SED $=1.494$. The calculated t-value is 120.which is not significant. Therefore null hypothesis no. 1.5 is accepted.

\section{FINDINGS OF THE STUDY}

Comparison of the scores of gender bias amongst adult and middle aged women, slum and non slum women, slum adult women and slum middle aged women.

1. It was found that there is no significant difference in the level of gender bias amongst adult and middle aged women.

2. It was found that gender bias is higher among slum women in comparison to non slum women.

\section{SUGGESTIONS}

Research and explorations are not the ending results but these always open the

Way for future endeavours. Similarly the present work is not the end in this area. In fact all the variables can never be studied in a single research.

The preset as its own limitations: certain humble suggestions are therefore given for further investigations.

1. For obtaining greater generality of the findings such studies must be conducted on another sample.

2. Large samples provide better results, but the present research work is confined to only 300 women. It cannot claim for its comprehensiveness. Future research may be conducted on even large sample.

3. The present study did not include male sample for comparison. Therefore, another study can be conducted comparing male and female of the same age group.

4. Since women despite of rapport hide experiences in their life due to the social structure of the Indian society. Therefore, more intensive observation of their family life is needed besides some tool using a projective technique can be used for in depth and correct understanding of their experiences regarding gender bias. 


\section{REFERENCES:}

Arokiasamy, P.( 2003), Gender preference, contraceptive use and fertility: Regional: and development influence.” International journal of population geography.

Gaarder, E. (2000) Gender Politics: the focus on women in the memory debates, Journal of Child Sexual Abuse, 9(1), pp 91-106.

Game, A \& Pringle, R. (1984) Gender at work, London, Pluto Press Ltd, ISBN (Paperback) 0 86104671 4, pp 147.

Goldberg R. (2001), Power in Sexual Relationships: An Opening Dialogue Among Reproductive Health Professionals, New York: Population Council.

Guilford, J.P and Fruchter, Benjamin (1981), Fundamental Statistics in Psychology and Education, McGraw- Hill International Book Company, London.

Mangal S.K, Statistics in Psychology and Education, PHI Learning Private Limited

Margrett, J.A. \& Marsiske, M. (2002) Gender differences in older adults' everyday cognitive collaboration, International Journal of Behavioural Development, 26(1), pp 45-59.

Nora, L.M. et. al. (2002) Gender discrimination and sexual harassment in medical Education: perspectives gained by a 14-school study, Academic Medicine, 77(12 Part 1), pp 12261234.

Tate, Merle. W, (1967). Statistics in Education and psychology, Macmillan Company. The American Heritage Dictionary. Dell Publishing Co., Inc., 1986.

Tomori, M. et. al. (2000) Gender differences in psychosocial risk factors among Slovenian adolescents, Adolescence, 35(139), pp 431-443.

Waldron, I. 1983. "Sex differences in human mortality: The role of genetic factors. Social Science Medicine 17(6): 321-33. 